\title{
Nobel Price for Father of the Efficient Market Hypothesis
}

Dear readers,

Followers of the efficient market hypothesis finally lived to see and me among them when Eugene F. Fama, of the University of Chicago, has earned on $14^{\text {th }}$ October 2013 the Nobel Prize in economics. To be more precise: the Sweden's Central Bank's prize in economic sciences for the development of economics in memory of A. Nobel. The father of the efficient market hypothesis, E. F. Fama assumes that stock prices are influenced by both fundamental and non-fundamental information. A liquid stock market is considered by Fama as efficient when it absorbs very quickly and accurately all important unexpected information. The market price of stocks on the liquid market is of the correct value, stocks are usually correctly priced and it is practically impossible to find undervalued or overvalued stock titles on the market. The term efficient is used in the sense of ability to handle the unexpected information. The Fama's work from 1965, ${ }^{1}$ in which he concluded that the prices on the American stock market with blue chips behave randomly, was of tremendous importance for the efficient market hypothesis. This work has become a watershed from which very often dates the formation of efficient market hypothesis in American literature. Fama's empirical research on the University of Chicago primarily focused on testing the hypothesis of efficient behavior of stock markets in the following decades. ${ }^{2}$

The efficient market hypothesis looks, at first glance, very logically, conclusively, and can explain the behavior of the stock prices in elegant manner. Fama's concept of the efficient markets does not anticipate that investors are able to identify the future market price faultlessly. It only claims that the current market price is the objective price, because it

1 Fama, E. F.: The Behavior of Stock Market Prices. Journal of Business, 1965, vol. 38, no. 1, pp. 34-105.

2 Viz Fama, E. F.: Efficient Capital Markets: A Review of Theory and Empirical Work. Journal of Finance, 1970, vol. 25, no. 2, pp. 383-417; Fama, E. F.: Efficient Capital Markets II. Journal of Finance, 1991, vol. 46, no. 2, pp. 1575-1617; Fama, E. F.: Market Efficiency, Long-Term Returns and Behavioral Finance. Journal of Financial Economics, 1997, vol. 49, no. 3, pp. 283-306. 
includes all available ratemaking information. The stock market prices then behave randomly because investors constantly analyze the stock market, reflecting new information in their investment decisions, trying to achieve maximum yield in view of the risk and the liquidity. Investors do therefore behave rationally, which then also means that even the stock market shows signs of rational behavior.

Stock markets can have different degrees of efficiency. The weakform efficiency means that current stock price contains all the information that can be obtained from historical data. Therefore the investor cannot predict the future using data from past translations and a movement and change of the stock price is random. If the past trend cannot be used for the prediction of the future development, then neither the Charles Dow's theory (constituting the theoretical basis of technical analysis) can clarify the nature of the behavior of stock prices.

The semi-strong efficiency is a situation in which current stock price includes not only historical data, but responds also very quickly and accurately to the publication of the new public information. If the stock market behaves efficiently in semi-strong form, then it is impossible to find incorrectly priced investment instruments on the stock market. In the semi-strong form of stock markets makes sense neither technical analysis, nor the theory of intrinsic value, which forms the core of fundamental analysis. Strong-form efficiency signifies that the current stock price reflects both public and private pricemaking information. In this form, not only an analytical activity in the form of a technical or fundamental analysis loses its importance, but also non-public information is becoming worthless, because they are absorbed in the stock exchange as well.

Efficient market hypothesis stands for an explanation of the behavior of stock prices and represents the mainstream of modern investment economics, which, however, has picked for its "laboratory" mainly the American stock market as the largest, the most liquid and the most advanced stock market of the world. The vast majority of the world's eminent investment economists agree that the most liquid stocks on the US stock market behave relatively economically efficiently. ${ }^{3}$ However, it

3 Some of the studies identify in the researched time-series indications of stock instrument price changes' dependency (the statistical ineffectiveness), but these are so tiny that it is impossible to use them practically and economically after taking the impact of transaction costs and taxes into account for a drafting of the investment strategy (economic effectiveness). 
should also be realized that the efficiency of stock markets is not constant, but may change over time, because not only stock market liquidity does varies, but also occasionally a significant and groundbreaking change in the investment environment occurs, which may complicate fast and accurate absorption of completely new ratemaking information for some time.

Testing of the efficient market hypothesis has gradually begun to focus on less liquid stock markets. It has also become a favorite theme of empirical research in the Central European area. Tests which examined the efficiency of those markets in the 1990s came to the conclusion that stock markets behave in most cases in an inefficient way. By contrast, the tests from the new millennium bring more and more evidence that the inefficiency of the most liquid stocks on the Central European markets has decreased significantly and that they behave even efficiently in the weak-form in some periods, which means that technical analysis does not bring benefit in framing stock strategy even on the underdeveloped Central European equity markets.

Supporters of the theory of efficient markets may, however, rejoice only partially, because this year's Nobel Prize for Economics acquired along with Fama also significant critics of Fama's explanation of the stock market behavior at the same time, both a representative of the theory of behavioral finance Robert J. Shiller (Yale University), and Lars Peter Hansen (University of Chicago), specializing in the econometric models of the behavior of equity instruments' prices.

prof. Ing. Petr MUSÍLEK, Ph.D. vice dean for science and doctoral study

Faculty of Finance and Accounting, University of Economics, Prague 